\title{
Analisis SOAR pada Strategi Pemasaran di Industri Jasa Finance
}

\section{SOAR Analysis on Marketing Strategies in the Finance Services Industry}

\author{
Adelia Alfama Zamista*, Hanafi \\ Program Studi Teknik Industri Sekolah Tinggi Teknologi Dumai \\ Jl. Utama Karya Bukit Batrem II, Dumai Timur - Riau \\ Email: alfadelia17@gmail.com
}

\begin{abstract}
ABSTRAK
Penelitian ini dilakukan pada industri jasa finance yang mengalami penurunan penjualan pada tahun 2018. Sehingga, studi ini perlu mengkaji menerapkan analisis SOAR pada strategi pemasaran pada studi kasus ini. Metode analisis yang digunakanpada penelitian ini adalah metode deskriptif dengan pendekatan kualitatif. data yang dikumpulkan dalam penelitian ini berupa informasi tentang strategi pemasaran dengan teknik pengumpulan data berupa wawancara dan observasi langsung. Hasil penelitian menunjukkan bahwa perusahaan ini memiliki banyak potensi positif yang menjadi kekuatan dan peluang usaha dari internal dan eksternal. Hasil penelitian ini diharapkan menjadi masukan dan acuan bagi perusahaan dalam menetapkan strategi penjulalan pada periode penjualan berikutnya.
\end{abstract}

Kata Kunci: Analisis Deskriptif Kualitatif, Industri Jasa Finance, SOAR, Strategi Pemasaran

\section{ABSTRACT}

This research was conducted in the finance service industry which experienced a decline in sales in 2018. Therefore, this study needs to examine applying SOAR analysis to marketing strategies in this case study. The analytical method used in this study is a descriptive method with a qualitative approach. The data collected in this study is information about marketing strategies with data collection techniques in the form of interviews and direct observation. The results showed that this company has a lot of positive potential that becomes the strength and business opportunities from internal and external. The results of this study are expected to be input and reference for companies in determining the selling strategy in the next sales period.

Keyword: Qualitative Study, Finance industry. SOAR, Marketing Strategi

\section{Pendahuluan}

PT Indomobil Finance Indonesia (PT IMFI) adalah perusahaan yang bergerak dalam jasa bisnis pembiayaan kendaraan bermotor dan alat berat dengan bentuk pembiayaan konsumen, sewa guna usaha, dan anjak piutang yang didirikan pada tahun. Dalam pengembangan usahanya PT Indomobil Finance yang lebih dikenal dengan sebutan IMFI membuka banyak cabang diseluruh Indonesia salah satunya di kota Dumai. Pembukaan cabang Dumai ini dilakukan karena dinilai bahwa potensi dan tingkat kebutuhan masyarakat Dumai terhadap kendaraan sangat tinggi. Hal ini menjadi kekuatan sekaligus kelemahan bagi PT IMFI. Kekuatan karena Dumai merupakan pangsa pasar yang luas, kelemahan karena di kota Dumai terdapat lebih dari sepuluh perusahaan yang bergerak di bidang yang sama.

Banyaknya perusahaan yang bergerak di bidang yang sama menuntut perusahaan untuk mampu bersaing. Target-target penjualan yang telah ditetapkan oleh perusahaan hanya akan bisa dicapai jika perusahaan memiliki rencana bisnis yang 
akurat. Selain perencanaan, dibutuhkan juga analisis terhadap bisnis yang dijalani untuk mendukung berhasilnya perencanaan tersebut. Analisis yang sering dilakukan perusahaan berkaiatan dengan strategi bisnis adalah analisis SWOT (Pasaribu, 2018).

SWOT merupakan akronim dari strenghts (kekuatan), weakness (kelemahan), opportunities (kesempatan), dan threats (ancaman) ke empat ini merupakan faktor-faktor strategis. Dilakukannya analisis terhadap faktor-faktor ini merupakan langkah yang dapat dilakukan sebelum merumuskan strategi bisnis (salah satunya strategi pemasaran) (Rangkuti, 1999). Namun selain analisis SWOT terdapat model analisis lainnya yaitu SOAR.

SOAR merupakan kerangka baru untuk perencanaan strategis. Menurut Stavros dan Hinrichs SOAR adalah kerangka perencanaan strategis dengan pendekatan yang berfokus pada kekuatan dan mencari untuk mengerti keseluruhan sistem dengan memasukkan suara dari stakeholders yang relevan. Pendekatan ini memungkinkan organisasi untuk membangun masa depan melalui kolaborasi, pemahaman bersama dan komitmen untuk bertindak (Stavros dkk, 2009).

Studi pendahuluan didapat data penjualan tiga tahun terakhir di PT IMFI Dumai dan diketahui bahwa selama tiga tahun terakhir terjadi fluktuasi penjualan. Yang cendrung menurun dari tahun ketahun. Seperti data penjualan dari tahun 20162017 terjadi penurunan yang awalnya terjual sebanyak 358 unit namun pada tahun 2017 hanya terjual sebanyak 269 unit. Sedangkan penjualan pada tahun 2018 adalah sebanyak 326 unit, meskipun angka inimeningkat dari penjualan tahun 2017, namun jumlah ini tidak lebih baik dari data penjualan tahun 2016. Masalah ini menunjukkan adanya indikasi kurang efektifnya strategi pemasaran yang diterapkan di PT IMFI Dumai. Oleh karena itu perlu dilakukan analisis terhadap strategi pemasaran pada PT IMFI Dumai, yang kemudian hasil analisis diharapkan menjadi acuan bagi PT IMFI Dumai dalam merancang strategi pemasaran untuk periode berikutnya.

Berdasarkan studi pendahuluan peneliti mengidentifikasi beberapa masalah, yaitu: 1) ancaman dari kompetitor, 2) belum berkembangnya strategi untuk menngkatkan provit perusahaan Maka pada penelitian ini akan dilakukan analisis SOAR terhadap strategi pemasaran PT IMFI Dumai yang bertujuan agar PT IMFI mampu bertahan dalam kondisi persaingan bisnis yang semakin ketat.

\section{Metode Penelitian}

\section{Model Penelitian}

Penelitian ini mengunakan model penelitian kualitatif. Penelitian kualitatatif adalah penelitian yang bertujuan untuk memperoleh gambarn mengenai suatu hal menurut pandangan manusia yang diteliti (Flick, 2015). Dalam hal ini yang diamati adalah strategi pemasaran PT IMFI menurit pandangan pihak terkait, meliputi kepala cabang, karyawan, konsumen, serta mempertimbangkan pandangan pesaing.

Penelitian ini mempertimbangkan beberapa hal diantaranya:

\section{Manajemen Pemasaran}

William J. Stanton menyatakan pemasaran adalah suatu sistem total dari kegiatan bisnis yang dirancang untuk merencanakan, menentukan harga, promosi dan mendistribusikan barang-barang yang dapat memuaskan keinginan dan mencapai pasar sasaran serta tujuan perusahaan.

Philip Kotler menyatakan pemasaran adalah proses sosial dan manajerial dengan mana seseorang atau kelompok untuk memperoleh apa yang mereka butuhkan dan inginkan melalui penciptaan dan pertukaran produk dan nilai (Kotler2008).

Beberapa pernyataan ahli tersebut dirangkum oleh Sunyoto dalam bukuya sehingga dapat disimpulkan bahwa pemasaran adalah kegiatan menyeluruh, terpadu dan terencana yang dilakukan oleh perusahaan untuk mempromosikan dan mendistribusikan barang, jasa, dan ide kepada pasar untuk mencapai tujuan dari perusahaan (Srinadi, 2016).

Sunyoto juga menyatakan pemasaran merupakan ujung tombak perusahaan. Dalam dunia persaingan yang semakin ketat, perusahaan dituntut agar tetap bertahan hidup dan berkembang. Oleh karena itu seorang pemasar harus dituntut untuk memahami permasalahan pokok dibidangnya dan menyusun strategi agar dapat mencapai tujuan perusahaan. Berikut ini beberapa pengertian mengenai pemasaran (Sunyoto, 2012).

Gambar 1 menunjukkan perkembangan manajemen pemasaran mulai dari adanya kebutuhan manusia, adanya peningkatan usaha, adanya peningkatan taraf hidup masyarakat, sistem ekonomi yang terbatas, timbulnya persaingan, adanya kegiatan produksi dan konsumsi, tingkat 
keuntungan dan tingkat harga, dan sistem pemasaran terpadu.

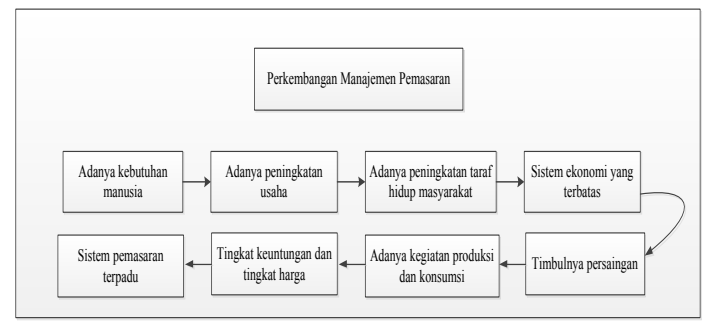

Gambar 1. Perkembangan Manajemen Pemasaran Sumber: (Sunyoto, 2012)

Pemasaran tidak sama dengan penjualan. Kegiatan pemasaran itu luas, bukan sekedar menjual barang, melainkan segala aktifitas yang berhubungan dengan arus barang sejak dari tangan produsen sampai ke tangan konsumen akhir. Termasuk dibidang pemasaran antara lain saluran distribusi, kebijaksanaan produk, periklanan, seni menjual, promosi penjualan, penyimpanan dan pergudangan produk, transportasi, kuota, kebijaksanaan pelayanan, daerah penjualan, pengawasan penjualan dan organisasi penjualan (Kotler, 2008).

Maka dalam penelitian ini yang dilakukan adalah analisis strategi pemasaran bukan hanya aspek penjualan, karena penjualan itu sendiri merupakan bagian dari pemasaran.

\section{Promosi}

Indriyo Gitosudarmo menyatakan promosi merupakan kegiatan yang ditujukan untuk memengaruhi konsumen agar mereka dapat menjadi kenal akan produk yang ditawarkan oleh perusahaan kepada mereka dan kemudian mereka menjadi senang lalu membeli produk tersebut. Adapun alatalat yang digunakan untuk mempromosikan suatu produk dapat dipilih beberapa cara, yaitu iklan, promosi penjualan, publisitas, personal selling yang disebut bauran promosi. Bruce J.Walker membagi lima metode promosi meliputi penjualan tatap muka (personal selling), periklanan (advertising), promosi penjualan (sales promotion), publisitas (publicity), hubungan masyarakat (public relation) (Sunyoto, 2012).

Kegiatan promosi juga merupakan salah satu kegiatan yang dijalankan oleh PT IMFI. Kelima metode promosi seperti yang dikemukakan oleh Walker juga diterapkan oleh PT IMFI dengan sales marketing sebagai roda utama perusahaan.
Promosi yang merupakan bagian dari pemasaran tidak hanya dilakukan untuk promosi produk melainkan juga untuk jasa. Pada dasarnya program promosi jasa mempunyai tiga tujuan, yaitu:

1. Memanfaatkan jasa-jasa secara paling menarik.

2. Membuat penawarannya lebih mudah dibedakan dari tawaran pesaingnya.

3. Mampu membuat reputasi yang baik, sehingga orang sangat terkesan terhadap jasa tersebut.

Adapun cara untuk meningkatkan produktifitas jasa, dapat dilakukan dengan cara sebagai berikut:

1. Memberikan pendidikan dan program latihan, tidak hanya untuk meningkatkan keahlian, tetapi juga untuk menciptakan agar para pekerja berusaha seefesien mungkin.

2. Memberikan teknologi baru dan metode-metode yang sesuai dengan industri jasa tersebut sehingga produktifitas dapat meningkat.

3. Melakukan spesialisasi usaha.

4. Melakukan konsolidasi organisasi.

\section{Strategi Pemasaran Jasa}

Jasa adalah segala sesuatu yang memiliki nilai jual dalam bentuk pelayanan yang diberikan kepada konsumen. Sementara perusahaan yang memberikan operasi jasa adalah perusahaan yang memberikan konsumen produk jasa baik yang berwujud atau tidak berwujud seperti jasa transportasi, jasa hiburan, jasa pendidikan dan restoran (Assauri, dkk, 2011).

Karakteristik jasa dalam hal ini dibedakan menjadi empat, yaitu tidak berwujud, tidak dapat dipisahkan, heterogenitas, dan cepat hilang dan permintaan yang fluktuasi.

1. Tidak berwujud

Jasa mempunyai sifat tidak berwujud karena tidak bisa dilihat, diraba, didengar atau dicium sebelum ada transaksi pembelian. Agar kepercayaan konsumen dapat ditingkatkan, ada beberapa hal yang perlu diperhatikan oleh pemilik jasa, yaitu:

a) Meningkatkan visualisasi jasa.

b) Permberi jasa tidak hanya menggambarkan ciri-ciri suatu jasa, tetapi justru lebih menekan manfaat dari jasa tersebut.

c) Penataan fisik, harus menjurus pada pelayanan yang cepat dan efesien. Harus menimbulkan kesan yang bersih dan rapi. 
d) Penataan dokumentasi, harus dilakukan dengan penataan yang rapi, terjamin keamanannya dan efesien.

2. Tidak dapat dipisahkan

Suatu bentuk jasa tidak dapat dipisahkan dari sumbernya, apakah sumber itu merupakan orang atau mesin, apakah sumber itu hadir atau tidak hadir, produk fisik yang berwujud tetap ada.

3. Heterogenitas

Industri jasa atau penjual jasa individu tidak mungkin mengadakan standardisasi output. Setiap unit jasa itu berbeda satu sama lain.

4. Cepat hilang dan permintaan yang fluktuasi

Jasa itu cepat hilang dan tidak dapat disimpan, dan pasaran jasa itu berubah-ubah menurut musim, menurut jam, dan hari. Karena cepat rusak dan permintaan yang berubah-ubah, maka perlu ada pengelolaan yang tepat. Misalnya melalui kemampuan petugas kelengkapan dan pemeliharaan sarana dan prasarana.

\section{SOAR}

Soar merupakan akronim dari strenght (kekuatan), opportunity (kesempatan), aspiration (aspirasi), dan result (hasil). SOAR merupakan kerangka baru perencanaan strategis yang dikembangkan oleh Stavros, Cooperider dan Kelley pada tahun 2009.

SOAR mengintegrasikan appreciate inquiry (AI) dengan membingkai ulang perencanaan strategis SWOT. Perbadaan mendasar SOAR dan SWOT adalah dilibatkannya stakeholder dalam mengidentifikasi dan menganalisis kekuatan serta peluang sehingga menciptakan aspirasi, tujuan, strategi, komitmen untuk memperoleh hasil.

Stakeholder yang diambil pendapatnya pada SOAR antara lain customer, pekerja, pemegang saham, anggota dewan, supplier, volunteer, serta masyarakat dari dampak organisasi. Ketika tidak semua stakeholder

mampu berpatisipasi, tiap kelompok ada stakeholders yang mewakilkan untuk :

1. Mengidentifikasi dan membangun kekuatan.

2. Menghubungkan dan memperjelas nilai, visi, dan misi yang ditetapkan.

3. Menemukan peluang keuntungan yang organisasi ingin raih.

4. Mengidentifikasi dan membangun kekuatan.

5. Menghubungkan dan memperjelas nilai, visi, dan misi yang ditetapkan.

6. Menemukan peluang keuntungan yang organisasi ingin raih.
7. Menentukan dan menyelaraskan tujuan dan sasaran organisasi.

8. Merevisi atau menciptakan tujuan, sistem, proses, serta struktur baru untuk mendukung tujuan.

9. Mengimplementasikan rencana untuk membimbing setiap hari dalam pengambilan keputusan dan tindakan.

Perbedaan lain dalam pendekatan SOAR adalah mengidentifikasi dan melebarkan kekuatan dan peluang dibandingkan dengan menelusuri masalah, kekurangan, kelemahan dan ancaman. Kelemahan dan ancaman tidak diabaikan, namun mereka dibingkai ulang dan memberikan fokus yang sesuai dengan peluang dan hasil percakapan sehingga kekurangan dan ancaman dapat dikurangi atau diubah menjadi kekuatan (Stavros dan Saint, 2010).

\section{Model Penelitian}

Penelitian ini mengunakan model penelitian kualitatif. Penelitian kualitatatif adalah penelitian yang bertujuan untuk memperoleh gambarn mengenai suatu hal menurut pandangan manusia yang diteliti ${ }^{[9]}$. Dalam hal ini yang diamati adalah strategi pemasaran PT IMFI menurit pandangan pihak terkait, meliputi kepala cabang, karyawan, konsumen, serta mempertimbangkan pandangan pesaing.

\section{Data}

Data pada penelitian ini merupakan segala hal yang berkaiatan dengan strategi pemasaran yang diterapkan pada PT IMFI. Sumber data pada penelitian ini adalah seluruh karyawan di PT IMFI meliputi kepala cabang, HRD, kolektor, admin dan account officer, konsumen, serta perusahaan pesaing (kompetitor).

Metode pengumpulan data pada peelitian ini adalah wawancara terstruktur dan dokumentasi. Adapun teknik analisis data adalah menggunakan analisis SOAR SOAR adalah penggunaan kekuatan dan peluang yang dimiliki perusahaan untuk menghasilkan aspirasi dan hasil. SOAR melibatkan seluruh tingkatan dan area fungsional dalam sebuah organisasi. Dengan SOAR, pusat perhatian ada pada organisasi dan memperbesar apa yang saat ini sudah dilakukan dengan baik, dibandingkan berkonsentrasi pada ancaman/kelemahan yang dihadapi. Analisis SOAR dimulai dengan melakukan analisis pada lingkungan eksternal dan internal serta industri untuk mencari peluang apa 
yang tersedia. Kemudian seluruh peluang dan kekuatan yang dimiliki akan dimasukkan ke dalam analisis SOAR untuk kemudian menghasilkan aspirasi dan hasil. Analisis ini dipilih sebab SOAR memiliki kelebihan dimana pendekatan yang diterapkan fokus pada peluang dan kekuatan dibandingkan kelemahan dan ancaman (Chiu, 2019).

\section{Hasil dan Pembahasan}

\section{Internal PT IMFI}

Indomobil

Finance

Indonesia (Perseroan) adalah perusahaan yang bergerak dalam bisnis jasa pembiayaan kendaraan bermotor dan alat berat dengan bentuk pembiayaan konsumen, sewa guna usaha dan anjak piutang yang didirikan pada tahun 1993. Pada tahun 2003, setelah pengambilalihan saham Marubeni Corporation oleh Indomobil Grup maka Perseroan mengubah namanya menjadi PT Indomobil Finance Indonesia.

Melalui strategi bisnis yang terus diselaraskan dengan tuntutan perkembangan iklim usaha, Perseroan tetap menjaga komitmen untuk menjadi perusahaan pembiayaan yang handal dan terpercaya di Indonesia.

Visi PT IMFI yaitu menjadi perusahaan pembiayaan produk-produk Indomobil Group yang terbaik dalam hal kepuasan pelanggan dan terbesar dalam hal jumlah pembiayaan dan perolehan tingkat keuntungan bagi para pemegang saham.

Struktur organisasi PT IMFI terdiri dari kepala cabang, HRD, kolektor, admin dan account officer. Kepala Cabang yang mempunyai tugas utama untuk menentukan kebijakan yang dilaksanakan perusahaan dan melakukan penjadwalan seluruh kegiatan perusahaan. Salah satu tugas Kepala Cabang yaitu mengkoordinasikan dan mengendalikan kegiatan-kegiatan di bidang administrasi keuangan, kepegawaian dan kesekretarian. Human Resources Departement (HRD) mempunyai tugas salah satunya yaitu menetapkan prosedur kegiatan perusahaan untuk mencapai sasaran yang ditetapkan perusahaan dan mengadakan pengangkatan, mutasi dan pemberhentian karyawan beserta gajinya. Admin memiliki tugas untuk mengatur segala kegitan administrasi Account Officer (AO) beserta kegiatan yang berada di kantor. Admin Collector memiliki tugas untuk mengontrol kegiatan kolektor, menelfon konsumen, menginput tagihan kolektor. Account Officers memiliki tugas untuk mencari berkas dan melakukan survey serta bertanggung jawab untuk berkas yang didapatkan. Collector memiliki tugas mengembalikan aset perusahaan serta membuat konsumen yang macet menjadi lancar.

\section{Analisis Lingkungan Eksternal Ekonomi}

Bank Indonesia menyatakan pertumbuhan ekonomi pada 2019 hanya mencapai 5,05 persen, namun pada 2020 berpeluang naik menjadi 5,1 persen sampai 5,5 persen (Departemen Komunikasi BI, 2020). Peluang meningkatnya pertumbuhan ekonomi ini juga akan dirasakan oleh berbagai pihak yang kemudian akan berdampak pada daya beli masyarakat.

\section{Sosial Budaya}

Transportasi sudah menjadi kebutuhan utama bagi masyarakat untuk melakukan aktivitasnya. Berdasarkan data Badan Pusat Statistik tercatat bahwa jumlah kendaran bermotor selalu meningkat tiap tahunnya. Data tahun 2017-2018 menunjukkan bahwa terjadi peningkatan jumlah kendaran bermotor sebesar 9.646.941 unit dari empat jenis kendaraan bermotor (mobil penumpang, mobil bis, mobil barang, dan sepeda motor) (BPS, 2019).

Peningkatan jumlah kendaraan bermotor setiap tahunnya ini menunjukkan bahwa aspek sosial budaya pun menjadi peluang bagi PT IMFI.

\section{Politik dan hukum}

Banyaknya program keringanan pajak bermotor, kemudahan urusan ganti nama kendaraan bermotor, serta pemutihan denda pajak menjadi beberapa alasan politik dan hukum menjadi peluang bagi pasar kendaraan bermotor (Dewi, 2019).

Teknologi

Kemajuan teknologi membuka peluang yang besar bagi banyak industri dan pemasarannya termasuk pemasaran kendaraan bermotor (Chiu, 2019). Hampir setiap tahun perusahaan yang memproduksi kendaraan bermotor mengeluarkan varian baru dengan klaim lebih canggih, lebih irit, lebih, gesit ataupun lebih ramah lingkungan. Hasil pengamatan dilapangan memperlihatkan bahwa 
masyarakat mudah terpengaruh untuk membeli varian baru kendaraan bermotor, umunya dibeli $\mathrm{dg}$ cara kredit hal ini jelas merupakan peluang bagi PT IMFI.

\section{Analisis SOAR \\ Strenght (Kekuatan)}

Berdasarkan hasil wawancara dengan kepala cabang dan ditambah dengan data hasil wawancara dengan karyawan PT IMFI dikatahui bahwa PT IMFI memiliki berbagai hal positif (kekuatan) yaitu:

1. Pendekatan secara berkala tehadap sales, supervisor (spv), dan kacab (kepala cabang) dealer.

2. Pelayanan yang cepat, memuaskan kepada dealer dan konsumen seperti keputusan hasil survey yang cepat, survey diluar jam kerja.

3. Melakukan follow up terhadap konsumenkonsumen IMFI Cabang Dumai yang sudah lunas, dimana konsumen yang di follow up hanyalah konsumen yang memiliki riwayat pembiayaan yang baik.

4. Account Officer (AO) aktif mencari aplikasi tidak hanya mengandalkan dari dealer saja, melainkan AO bisa mendapatkan aplikasi dari luar dealer dengan cara melakukan follow up konsumen repeat order (RO) IMFI atau canvasing disekitar daerah tempat tinggal AO.

5. AO mempunyai hubungan yang baik dengan setiap karyawan dealer seperti sales, SPV, dan kacab delaer.

6. Kemudahan transaksi untuk konsumen RO

7. Adanya program kick back atau subsidi dari leasing yang diberikan kepada dealer

\section{Opportunities (Peluang)}

Melihat kondisi internal dan eksternal PT

IMFI peluang-peluang yang dimiliki PT IMFI dalam menjalankan usahanya antara lain:

1. Fakta bahwa transportasi sudah menjadi kebutuhan utama bagi masyarakat dalam menjalakan aktivitas dan peluang meningkatnya pertumbuhan ekonomi indonesia yang secara tidak langsung akan meningkatkan daya beli masyarakat terhadap kendaraan bermotor.
2. Kemajuan teknologi yang menyebabkan terus munculnya kendaraan dengan inovasi terbaru membuat masyarakat terdorong untuk membeli jenis kendaraan terbaru sehingga banyaknya potensi konsumen RO di PT IMFI

3. Banyaknya dealer yang bisa diajak untuk bekerjasama. Contohnya sampai tahun 2018 PT IMFI belum bekerja sama dengan daelar Yamaha. Kemungkinan untuk bekerjasama dengan Yamaha tentu menjadi peluang untuk meningkatkan pemasaran di PT IMFI.

4. Masih banyak daerah yang dapat dijangkau oleh AO. Jika AO dapat menjangkau daerahdaerah yang selama ini belum dilakukan promosi tentu akan menjadi peluang bagi PT IMFI.

\section{Aspiration (Aspirasi)}

Aspirasi adalah hal yang ingin dituju oleh PT IMFI. Dalam penelitian ini goals dari PT IMFI adalah:

1. Meningkatkan jumlah pengguna jasa pembiayaan kendaraan bermotor dan alat berat PT IMFI

2. Memiliki tim yang solid dan berkualitas

\section{Result (Hasil)} merupakan indikator tingkat kesuksesan perusahaan adalah sebagai berikut:

1. Peningkatan jumlah konsumen

2. Peningkatan jumlah pembelian kendaraan bermotor melalui PT IMFI

3. Turn over karyawan rendah

\section{Kesimpulan}

PT IMFI sebagai perusahaan pembiayaan dikatakan berhasil jika banyak masyarakat yang mempercayainya untuk memberikan pinjaman atau talangan dana. Hal ini dapat terealisasi karena PT IMFI memiliki banyak hal-hal positif yang menjadi kekuatan dan berbagai peluang usaha baik dari segi internal maupun eksternal. Salah satu kekuatan PT IMFI adalah disekotor konsumen repeat order (RO) dan account officer yang mampu menjalankan tugasnya dengan baik. 
Adapun segi peluang juga berkaitan dengan RO dan AO.

\section{Daftar Pustaka}

Assauri, Sofjan. 2011. "Manajemen Pemasaran: Dasar, Konsep dan Strategi”, Jakarta: Cetakan 11. Penerbit PT Rajagrafindo Persada.

Badan Pusat Statistik. 2019. Perkembangan Jumlah Kendaran Bermotor Menurut Jenis 19492018.

https://www.bps.go.id/linkTableDinamis/view/ $\mathrm{id} / 1133$

Chiu, C. 2019. Analisis Strategi SOAR PT XYZ dalam Meningkatkan Penjualan Bahan Baku Kimia untuk Industri Tekstil, Kayu, Pakaian dan Deterjen. Jurnal Manajemen Bisnis dan Kewirausahaan, Vol 2

Departemen Komunikasi BI. 2020. . Laporan Tahunan Kinerja Ekonomi. https://www.bi.go.id/id/ruang-media/infoterbaru/Pages/Laporan-Akuntabilitas-AwalTahun-2020-Bank-Indonesia.aspx

Dewi, R.S. 2019. Denda Pajak Kendaraan di Riau Diputihakn, Ini Jadwalnya. GoRiau.com https://www.goriau.com/berita/baca/dendapajak-kendaraan-di-riau-diputihkan-inijadwalnya.html

Flick. U. 2015. Introducing ResearchMethodology: a Beginners Guide to Doing a Research. Los Angeles: Sage

Kotler, P.G. 2008. Prinsip-prinsip Pemasaran. Jakarta: Erlangga

Pasaribu. H.F. 2018. "Penerapan Analisis SWOT dalam Strategi Pemasaran pada PT Arma Anugerah Abadi Medan. Skripsi Fakultas Ekonomi dan Bisnis Islam Universitas Islam Negeri Sumatera Utara Medan. Diakses pada: 21-Desember-2019

http://repository.uinsu.ac.id/5198/1/SKRIPSI \%20HIDAYATI\%20FAUZIAH\%20P_EKI.p df

Srinadi, N.L.P. 2016. Analisis SWOT sebagai dasar Menentukan Strategi Pemasaran Kompetitif (Studi Kasus: Usaha Jasa Dekorasi X). Seminar Nasional Teknologi Informasi dan Komunikasi 2016 (SENTIKA 2016)

Stavros, J. M. \& Saint, D. 2010. SOAR: Linking Strategy and $O D$ to Suistainable Performance. Practicing Organizatiton Development: A Guide for Leading Change
Stavros, J.M \& Hinrichs, G. 2009. The Thin Bookof Soar: Building Strenght-based Strategy. Unspecified

Sunyoto, Danang. 2012. "Dasar-dasar Manajemen Pemasaran: Konsep, Strategi, dan Kasus”, Yogyakarta: Cetakan 1. Penerbit PT Buku Seru. 